\title{
INTENSE DISTURBANCE ENHANCES PLANT SUSCEPTIBILITY TO HERBIVORY: NATURAL AND EXPERIMENTAL EVIDENCE
}

\author{
David A. Spiller ${ }^{1,3}$ And Anurag A. Agrawal ${ }^{2}$ \\ ${ }^{1}$ Section of Evolution and Ecology and Center for Population Biology, One Shields Avenue, University of California, \\ Davis, California 95616 USA \\ ${ }^{2}$ Department of Botany, University of Toronto, 25 Willcocks Street, Toronto, Ontario, Canada M5S 3 B2
}

\begin{abstract}
Following Hurricane Lili, which passed directly over the site of our ongoing study in Great Exuma, Bahamas, herbivory increased on devastated islands exposed to the storm surge, but not on protected islands. Observations suggested that foliage sprouting on severely damaged shrubs was more susceptible to herbivores than was new foliage on undamaged shrubs. To test this hypothesis, we conducted a controlled field experiment: hurricane damage was simulated by pruning shrubs on replicated islands. Seven months after the manipulation, herbivory was $68 \%$ higher on pruned shrubs than on controls. Leaf size and percentage of nitrogen were higher, and leaf toughness and trichome density were lower on pruned shrubs than on controls. The experimental results indicate that enhanced herbivory on exposed islands following Hurricane Lili was caused, at least in part, by increased susceptibility of the sprouted foliage to herbivorous arthropods. Because sprouting occurs on many woody plants following natural or anthropogenic disturbances, the findings in this study may have broad implications.
\end{abstract}

Key words: abiotic disturbance; Bahamas; Conocarpus erectus; foliage sprouting; food webs; herbivory; hurricanes; leaf damage; moths; pruning experiment; trichomes.

\section{INTRODUCTION}

Although numerous studies have demonstrated that natural disturbances play a major role in structuring species composition in biological communities (Connell 1978, Sousa 1984, Menge and Sutherland 1987), field studies focusing on how disturbances affect food web dynamics are rare (Power et al. 1996, Wootton et al. 1996). Following a catastrophic disturbance that kills most of the plants, herbivory may be intense because early-successional plant species are more susceptible to herbivores (Cates and Orians 1975, Sousa 1980, Lubchenco 1986, Bishop 2002). In the case of intense storms, however, woody plants are often blown down, but not killed, and regenerate by trunk or root sprouting (Bond and Midgley 2001). Regrowth foliage may have altered quality for herbivores because of younger leaf age, plant ontogeny (induced neotany), changes in levels of defense, or changes in allocation patterns (Rockwood 1974, Coley and Barone 1996, Karban and Baldwin 1997). We examined the effects of such disturbance-mediated phenotypic modifications on herbivory following natural and simulated intense hurricane damage in the Bahamas.

In October 1996, we had just finished our annual survey of the biota inhabiting small islands located on both sides of the very large island of Great Exuma when the eye of Hurricane Lili passed directly over our study

Manuscript received 19 April 2002; revised 27 August 2002; accepted 30 August 2002. Corresponding Editor: S. C. Pennings.

${ }_{3}^{3}$ E-mail: daspiller@ucdavis.edu site with sustained winds of $\sim 185 \mathrm{~km} / \mathrm{h}$ and a $5-\mathrm{m}$ storm surge. A map of the study site showing the path of Lili and description of the study islands may be found in Spiller et al. (1998). Because Lili's approach was from the southwest, study islands on that side of Great Exuma were exposed to the full force of the storm surge, the most destructive component of the hurricane, whereas study islands located on the other side were protected. The surge removed most of the standing biomass of vegetation on the exposed islands (Fig. 1), whereas damage to the vegetation on the protected side was minimal. During the week following the storm, we found that all lizard and spider populations had been exterminated on exposed islands; in contrast, no lizard population and only small populations of spiders had been exterminated on protected islands (Spiller et al. 1998).

As part of an ongoing food web study, we had measured amounts of leaf damage on Conocarpus erectus (Combretaceae; buttonwood), a common seashore shrub, for three consecutive years before the hurricane. Foliage color of $C$. erectus varies from green to silver (Fig. 1), depending on the density of trichomes on the surface of the leaves. A previous study showed that green leaves (few trichomes) were more damaged than silver leaves (more trichomes), suggesting that the trichomes reduce herbivory (Schoener 1988). During the hurricane, all study shrubs on exposed islands were reduced to stumps by the surge, but regenerated by sprouting during the following year. Damage on the sprouted foliage was usually high and we frequently found moth larvae (Collomena filifera and other un- 

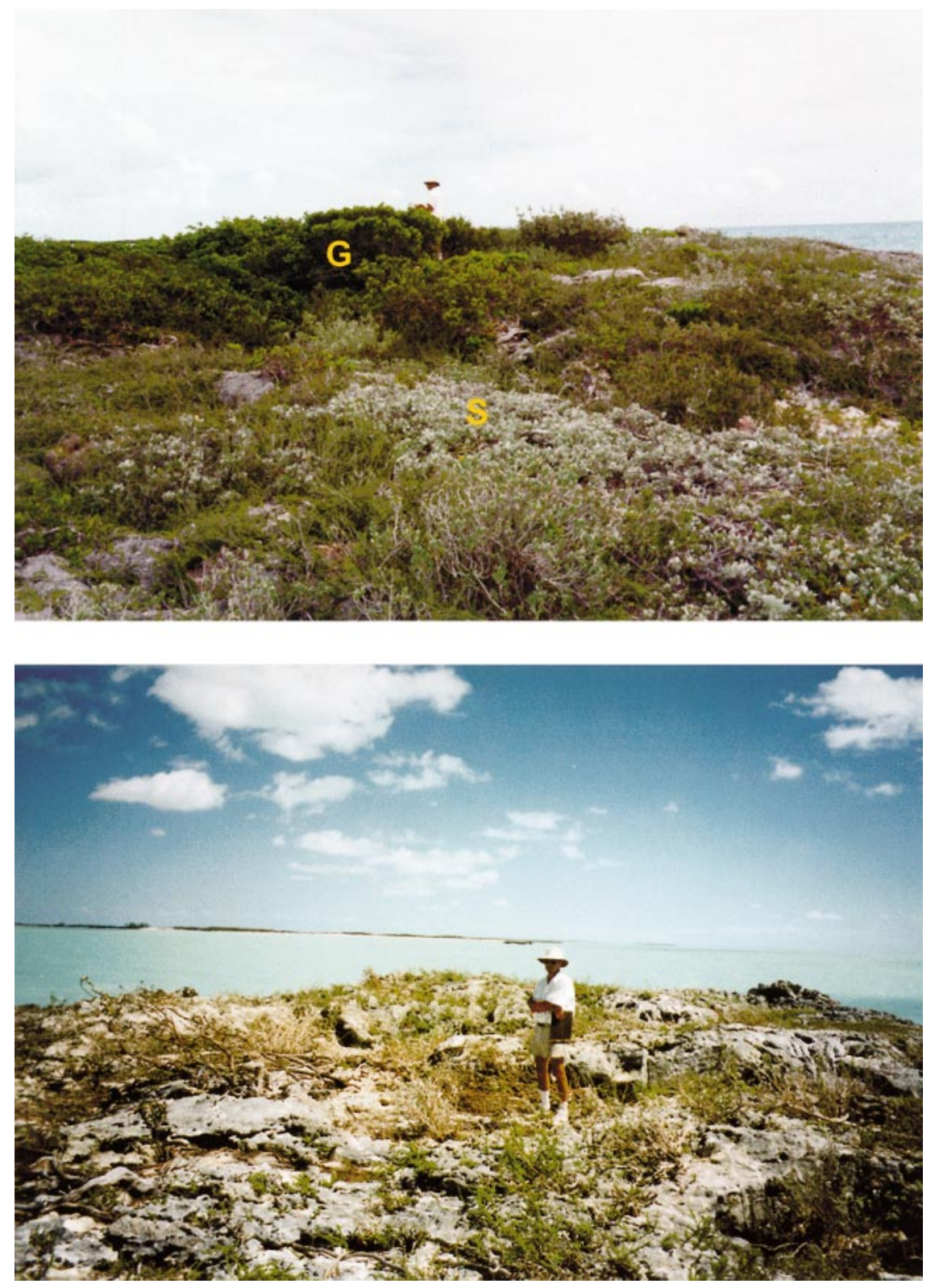

FIG. 1. Photographs of an exposed study island near Great Exuma, Bahamas, the week before and after Hurricane Lili. Green $(\mathrm{G})$ and silver (S) Conocarpus erectus are labeled in the top photograph.

identified species) consuming the leaves. We observed that on exposed islands, $C$. erectus with silver leaves before the hurricane sprouted green leaves in the year after and then reverted to producing silver leaves in the following year. In addition, the sprouted foliage appeared to be very lush, possibly because the leaves were larger, more tender, or contained more nitrogen. In this paper, data on natural variation of leaf damage before and after the hurricane and a controlled field experiment indicate that the disturbance enhanced plant susceptibility to herbivory.

\section{Methods}

\section{Comparative study of herbivory on protected and} exposed islands

Samples of leaves were collected on eight protected and eight exposed islands in October 1994-1998. The 1996 samples were collected during the week before the hurricane. The number of shrubs sampled per island varied from one to four, depending on the availability of Conocarpus erectus. On each shrub, four random samples, each containing $\sim 20$ leaves, were obtained 
by looking away, reaching toward the shrub, and collecting leaves on the first branch contacted. Leaves were pressed and then photographed. Total leaf areas and damaged leaf areas were measured digitally using SigmaScan Pro Image Analysis System (SPSS, Chicago, Illinois, USA). The percentage of the leaf area damaged on each shrub was computed by summing the total and damaged areas of all of the leaves sampled. After the hurricane, relative abundance of aerial arthropods was measured at 2-4 mo intervals with sticky traps. On each of five protected and 10 exposed islands, six traps $(22 \times 14 \mathrm{~cm}$ sheets of clear plastic coated with Tangletrap [Tanglefoot, Grand Rapids, Michigan, USA] adhesive on one side) were tied to the vegetation $0.1-0.5 \mathrm{~m}$ above the ground. After $24 \mathrm{~h}$, the taxon (to order or lower when possible) of each arthropod caught in each trap was recorded in the field. For brevity, we present abundance only for moths (all Lepidoptera caught) because they were obviously the major herbivores; other taxa are discussed. Data were statistically analyzed by performing a multivariate repeatedmeasures analysis (SAS Institute 1999) on the mean values for each island; location (protected vs. exposed) was the between-subjects factor and year was the within-subjects factor. Leaf damage was arcsine square-root transformed and the number of moths was log-transformed for analyses (raw values are presented in all figures).

\section{Field experiment}

We hypothesized that enhanced herbivory on exposed islands following Hurricane Lili was caused, at least in part, by increased susceptibility of the sprouted foliage to herbivorous arthropods. To test the hypothesis, on 12 exposed islands we tagged matched pairs of similar C. erectus shrubs; one member of each pair was randomly assigned to be the treatment, leaving the other as the unmanipulated control. Shrubs were paired according to size, foliage color, and location (members of each pair were 2-6 m apart). Each island had one pair of shrubs, except for the two largest, which had two pairs. In October 2000, all branches that had sprouted since the hurricane were pruned on the treatment shrubs so that they resembled their condition immediately following the hurricane. The shrubs were reduced to stumps and virtually all apical meristems were removed. In addition to removing most of the aboveground biomass, the storm surge may have affected plants via increased salinity levels, exposed roots through soil erosion, and deposition of wrack. However, C. erectus plants growing very close to shore do not appear to be adversely affected by periodic saltwater flooding during spring high tides. The small study islands contained very little soil (most of the roots were deeply embedded in the rocky substrate), and wrack deposition was minimal after the hurricane (Fig. 1). Therefore, we suggest that pruning simulated the major effect of the storm surge on plants, but not all of the effects. The experiment was conducted on exposed islands, rather than on protected islands, because we suspected that other abiotic and biotic factors present on protected islands may prevent the herbivores from responding to the manipulation (see Discussion). Although the experiment was initiated four years after the hurricane, the height and possibly other aspects of the shrubs on exposed islands had not fully recovered. However, two years after the hurricane, leaf damage returned to the about the same level measured before the hurricane.

In October (immediately prior to the manipulation) and December 2000, four samples of leaves were taken on each shrub following the procedure just described. Because susceptibility to herbivory may vary with leaf age (Rockwood 1974, Coley and Barone 1996), in December 2000, when all of the leaves on pruned shrubs were relatively young, only correspondingly young leaves located on the distal ends of branches were collected on control shrubs. To control for leaf age more precisely, we tagged four randomly chosen branches and marked the most distal leaves present with ink in December 2000. Only leaves that emerged thereafter were collected in May 2001. The same procedure was performed in May 2001 to control for leaf age in the October 2001 samples. For each date, leaf area and percentage of the leaf area damaged on each shrub were measured and computed as previously described. Trichomes were counted under a dissection microscope and leaves were classified as silver ( $\geq 30$ trichomes/ $\mathrm{mm})$ or green $(<30$ trichomes/mm) as in Schoener (1988). We examined 10 randomly selected leaves from each experimental shrub and the proportion of leaves that were silver was the trichome index. Toughness was measured on five randomly chosen leaves from each shrub, using a force gauge penetrometer (Type 516, Chatillon, New York, New York, USA); the force required to punch a hole in each leaf was recorded. Total leaf nitrogen and carbon were measured with a LECO 600 CHN analyzer (LECO, St. Louis, Missouri, USA). Two sticky traps (as previously described) were tied onto the branches of 12 pruned and 12 control shrubs in October 2000 (prior to the experiment) and in May and October 2001 (during the experiment). Traps were not used in December 2000 because the sprouted branches on the pruned shrubs were too short and tender to hold a trap.

For each variable, mean values for each shrub taken each sampling date after the manipulation were analyzed using a multivariate repeated-measures analysis; the experimental units were individual shrubs, island and treatment (pruned vs. control) were between-subjects factors and sampling date was the within-subjects factor. Treatment effect was always a one-tailed test; a priori hypotheses were that pruned shrubs would have higher leaf damage and herbivore abundance, and that their leaves would be larger, more tender, have fewer trichomes, and contain more nitrogen. To test each hy- 
pothesis, we used the $P$ value for the overall treatment effect when the time $\times$ treatment interaction was not significant $(P>0.05)$. When the interaction was significant, treatment effects from separate ANOVAs on each sampling date were used; $P$ values were adjusted for multiple comparisons using the stepdown Bonferroni method (SAS Institute 1999). For descriptive purposes, adjusted $P$ values are given for all variables on all dates in the figures. Variation among islands accounted for much of the total variance, and differences between pruned and control shrubs are sometimes significant where raw standard errors overlap in the figures. To account for initial variation in trichome indices, we included values in October 2000 as a covariate in analyses of subsequent samples. Leaf area, leaf toughness, and number of moths were log-transformed, and percentage leaf area damaged, trichome index, and percentage nitrogen were arcsine square-root transformed for analysis. One pair of shrubs was omitted in the leaf analyses because herbivores (apparently moth larvae) ate virtually all of the leaves on the pruned shrub in May 2001.

\section{RESULTS}

\section{Comparative study of herbivory on protected and exposed islands}

Before the hurricane, leaf damage was higher on exposed than on protected islands (Fig. 2A). On exposed islands, in 1997 (one year after), leaf damage was 80\% higher than damage in the previous year, and damage in 1998 returned to about the pre-hurricane level. In contrast, leaf damage on protected islands remained relatively constant after the hurricane. In repeated-measures analysis, the overall difference between exposed and protected islands (location effect, $F_{1,14}=38.00, P$ $<0.0001)$ and variation among years $\left(F_{4,11}=15.62\right.$, $P=0.0002)$ were significant. The year $\times$ location interaction $\left(F_{4,11}=4.52, P=0.0211\right)$ was also significant, indicating that the hurricane differentially affected herbivory on exposed vs. protected islands.

Early in the year after the hurricane, abundance of moths was higher on protected than on exposed islands, but later in the year, moths became 4.6 times more abundant on exposed islands and tended to remain more abundant there during the following year (Fig. 2B). The overall difference between exposed and protected islands was not significant $\left(F_{1,13}=0.01, P=0.9376\right)$, but variation among sampling dates $\left(F_{5,9}=5.87, P=\right.$ $0.0111)$ as well as the date $\times$ location interaction $\left(F_{5,9}\right.$ $=9.30, P=0.0023$ ) were significant, indicating that after the hurricane, population dynamics of moths differed significantly on exposed vs. protected islands. Beetles (Artipus floridanus, Chaetocnema brunnescens, and two unidentified species) were occasionally observed consuming Conocarpus erectus, but their abundance in 1997 was lower on exposed than on protected islands (data not shown), suggesting that moths were the major herbivores responsible for the exceptionally high leaf damage on the exposed islands in 1997.

\section{Field experiment}

In October 2000 (just prior to pruning) and in December 2000 (two months after pruning), leaf damage on control and pruned shrubs did not differ significantly (Fig. 2C). In May 2001, mean damage was 68\% higher on pruned shrubs compared to controls. In October 2001, mean leaf damage on pruned shrubs decreased to the control level. In repeated-measures analysis on the three sampling dates after the manipulation, the date $\times$ treatment interaction was significant $\left(F_{2,12}=6.01\right.$, $P=0.0155)$; in separate within-date analyses, the treatment effect was significant in May $2001\left(F_{1,13}=9.81\right.$, adjusted $P=0.0120$ ), but not in the other two dates.

Mean numbers of moths caught in sticky traps on control and pruned shrubs were nearly identical just prior to the experiment (October 2000), whereas they were $47 \%$ higher on pruned shrubs in May 2001 and 97\% higher in October (Fig. 2D). The overall treatment effect was significant (repeated-measures analysis on both dates: $F_{1,11}=4.13, P=0.034$ ). In October 2001, moth abundance may have remained higher on pruned shrubs than on controls, even though leaf damage was about the same, because the abundance of moths (adult stage) caught in the traps in October 2001 corresponded to the abundance of larvae (foliage feeding stage) in May 2001, when leaf damage was higher on pruned shrubs. Numbers of beetles tended to be higher in traps on pruned shrubs than on controls, but the overall difference was not significant $\left(F_{1,11}=1.66, P=0.112\right)$, and numbers of beetles were only about half of those for moths, indicating that moths were the major herbivores responsible for higher leaf damage on pruned shrubs in May 2001. Numbers of hymenopteran parasitoids were significantly higher in traps on pruned shrubs than on controls $\left(F_{1,11}=3.26, P=0.049\right)$. Numbers of other potential predators (e.g., predatory hemipterans, spiders) caught in traps were extremely low and did not differ significantly on pruned and control shrubs. Therefore, higher moth abundance on pruned shrubs did not appear to be caused by a lack of natural enemies.

Measurements of leaf size, toughness, trichome index, and percentage nitrogen did not differ significantly for pruned and control leaves prior to the manipulation (Fig. 3). In December 2000, although leaves on pruned and control shrubs were about the same size, pruned leaves had $46 \%$ lower toughness, $56 \%$ lower trichome index, and $47 \%$ higher nitrogen. In May 2001, leaves on pruned shrubs were $34 \%$ larger and had $32 \%$ higher nitrogen than did controls, but toughness and trichome index did not differ significantly. In October 2001, leaves on pruned shrubs were $11 \%$ larger and had $48 \%$ lower trichome index, whereas toughness and nitrogen were nearly identical to those of controls. In repeated-

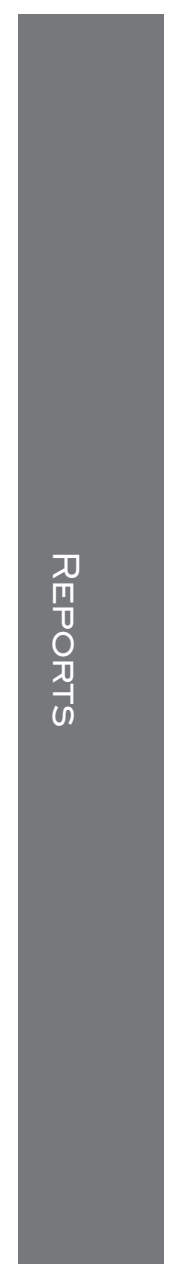


- Exposed islands

- Protected islands
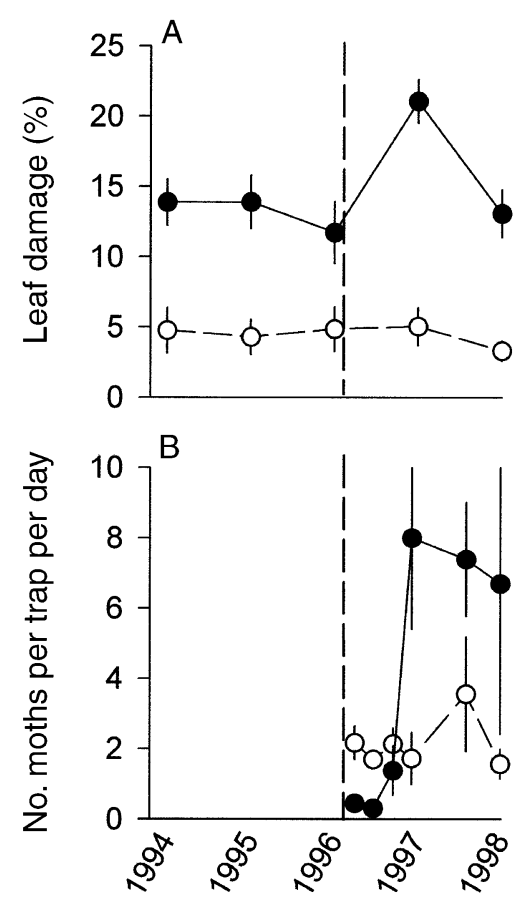

- Pruned

O Control
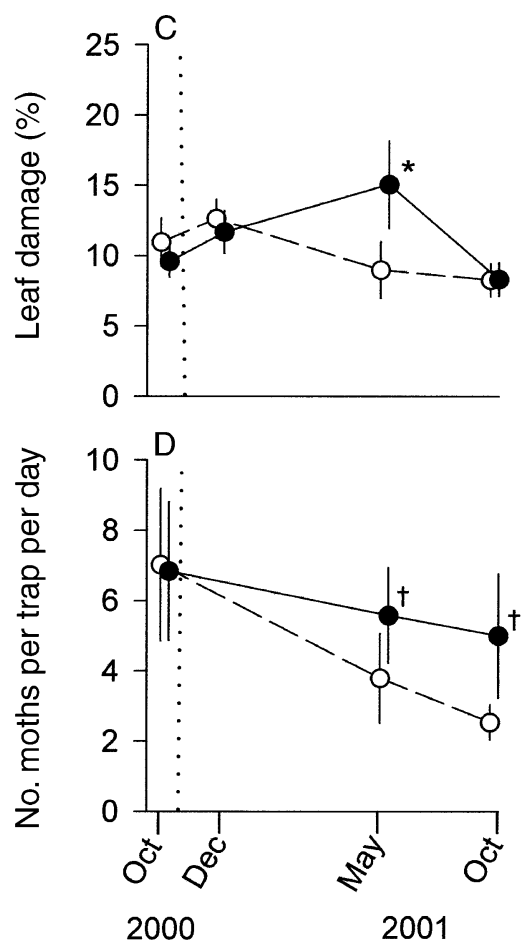

FIG. 2. (A, B) Herbivory on exposed and protected islands before and after Hurricane Lili: (A) mean ( \pm 1 SE) percentage of leaf area damaged; and (B) number of moths (mean $\pm 1 \mathrm{SE}$ ) caught in sticky traps. The vertical dashed line marks the occurrence of the hurricane. (C, D) Effect of experimentally pruning shrubs on exposed islands: (C) mean ( $\pm 1 \mathrm{SE})$ percentage of leaf area damaged; and (D) number of moths (mean $\pm 1 \mathrm{SE}$ ) caught in sticky traps. The vertical dotted line marks when the treatment shrubs were pruned. Significance of within-date ANOVA treatment effect (stepdown Bonferroni adjusted) is indicated as: $\dagger P<0.10, * P<0.05$.

measures analyses, the overall treatment effect was significant for leaf area $\left(F_{1,13}=7.30, P=0.0095\right)$, trichome index $\left(F_{1,12}=10.33, P=0.0037\right)$, and percentage nitrogen $\left(F_{1,13}=3.69, P=0.0384\right)$; the date $\times$ treatment interaction was not significant for these variables. For toughness, the date $\times$ treatment interaction was significant; in separate within-date analyses, the treatment effect was significant for December 2001 $\left(F_{1,13}=29.48\right.$, adjusted $\left.P=0.0003\right)$, but not for the other two dates. Percentage carbon of leaves on pruned and control shrubs was nearly identical (data not shown); the carbon-nitrogen ratio was significantly lower for pruned shrubs than for controls (overall treatment effect $F_{1,13}=5.22, P=0.0200$ ).

\section{DISCUSSION}

Our comparative study showed that in the year after the hurricane, Conocarpus erectus leaf damage increased on devastated islands exposed to the storm surge, but not on protected islands. During that year, we found numerous moth larvae in the sprouted foliage on exposed islands, and the abundance of adult moths caught in traps became much higher on exposed than on protected islands. Some shrubs were almost com- pletely defoliated. Therefore, our measurements on collected leaves underestimated the severity of herbivory on exposed islands because totally eaten leaves were not included (Lowman 1984). Our experimental results indicate that enhanced herbivory on exposed islands following Hurricane Lili was caused, at least in part, by increased susceptibility of the sprouted foliage to herbivorous arthropods.

Additionally, different dispersal abilities of species at different trophic levels may structure insular food webs (Holt 1996). Following Hurricane Lili, moths may have colonized the devastated exposed islands before their predators did. We note that on exposed islands, numbers of parasitoids caught in sticky traps were low during the year following the hurricane and increased during the second year, whereas the number of moths increased during the first year. Furthermore, mean leaf damage on exposed islands measured in the year after Lili (22\%; Fig. 2A) was higher than the maximum damage on pruned shrubs (15\%, Fig. 2C), suggesting that reduced predation or some other factor also may have enhanced herbivory following the hurricane. During the experiment, the number of parasitoids caught in sticky traps was higher on pruned shrubs than 

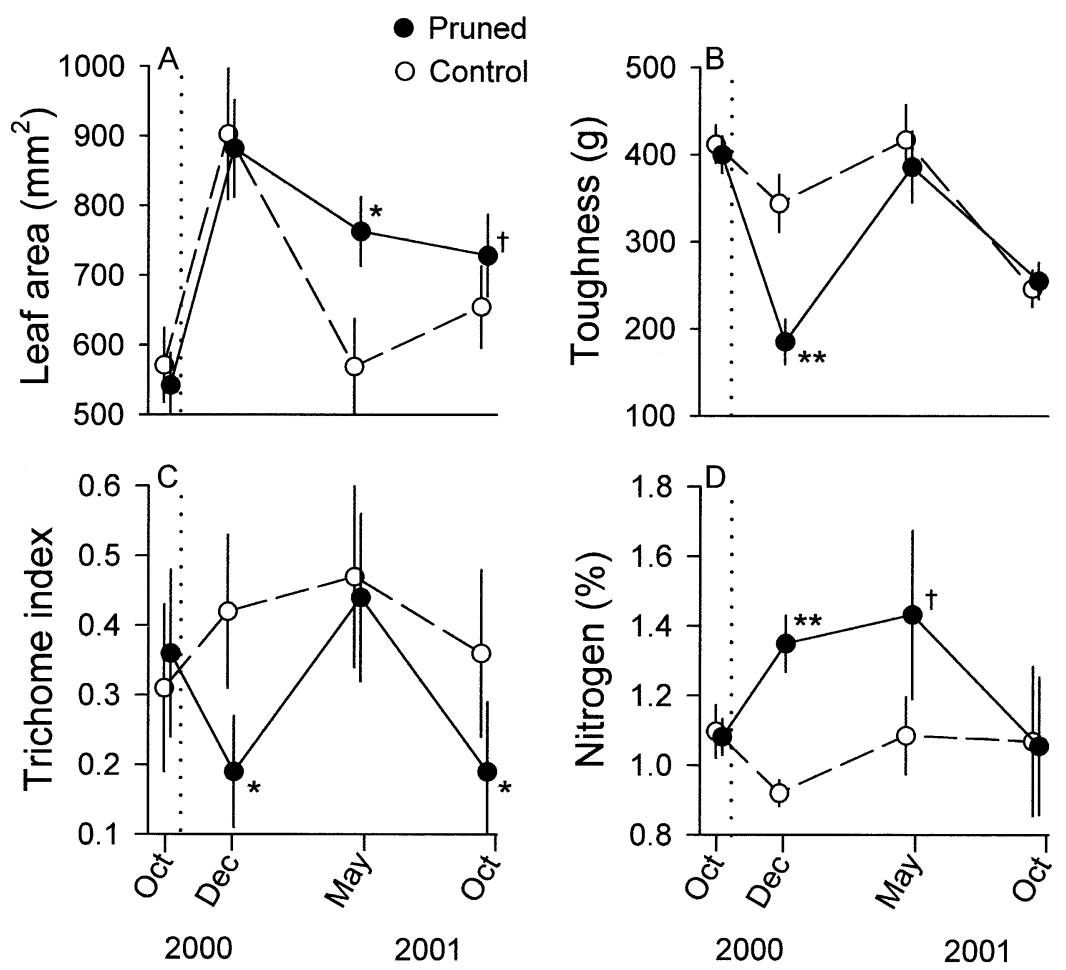

FIG. 3. Effect of pruning on leaf attributes: mean ( \pm 1 SE) values for $(A)$ leaf area; (B) toughness; (C) trichome index proportion of silver leaves; and (D) percentage nitrogen. The vertical dotted line marks when the treatment shrubs were pruned. Significance of within-date ANOVA treatment effect (stepdown Bonferroni adjusted) is indicated as: ${ }^{\dagger} P<0.10, * P$ $<0.05, * * * P<0.001$

on controls. Therefore, during the experiment these natural enemies may have reduced herbivore densities below the levels that occurred following the hurricane. A few of the exposed islands were colonized by lizards during the experiment, but their densities were very low and we found no significant difference in herbivory between islands with and without lizards.

Herbivory was higher on exposed than on protected islands even before the hurricane. Chronic physical stress (e.g., wind, salt spray) on exposed islands might have caused the plants to be more susceptible to herbivory than those on protected islands (Moon and Stiling 2000). The generally higher rainfall on the exposed than on the protected islands may be more favorable for the herbivores. Furthermore, because the exposed islands are much farther from Great Exuma than are the protected islands (Spiller et al. 1998), higher herbivory on exposed islands might have been due to the absence of some important predator or parasitoid species (Schoener et al. 1995). The most conspicuous predators on protected islands were insectivorous birds, which we rarely observed on exposed islands. Considering these factors, we suggest that the high level of herbivory observed only on exposed islands following the hurricane was partially caused by other abiotic and biotic factors in addition to increased plant susceptibility. Hence, experimental pruning of shrubs on protected islands might not lead to increased herbivory because plant response to this stress may interact with other environmental factors.

Although each of the four leaf attributes measured was significantly affected by pruning, nitrogen level appeared to correspond to the effect of pruning on herbivory better than did the other attributes. Both leaf damage and nitrogen content were substantially higher for the foliage of pruned shrubs than for controls in May 2001, and were nearly identical for pruned and control shrubs in October 2001 (compare Figs. 2 and $3)$. Leaf area was larger for pruned shrubs than for controls in May and October 2001, and toughness and trichome index were about the same for pruned and control leaves in May 2001. This suggests that leaf nitrogen was primarily responsible for the effect of pruning on herbivory. However, low toughness and trichome density for the leaves of pruned shrubs measured in December 2000 may have led to high abundance of herbivores during the next few months, followed by an induced response by the plants causing increased toughness and more trichomes for the leaves of pruned shrubs measured in May 2001. Studies on other plant species have demonstrated that an increase in trichomes can be induced by herbivory (Baur et al. 1991, Karban and Baldwin 1997, Agrawal 1999). Interestingly, the trichome index for pruned foliage decreased markedly in October 2001, when leaf damage decreased, suggesting that $C$. erectus may respond to 
levels of herbivory by varying the amounts of leaf trichomes. The interactive effects of plant damage, leaf trichomes, and herbivory in this system require further investigation. Although the intense damage caused by the storm surge, which resembled our experimental pruning, might have affected the measured leaf attributes similarly, these attributes were not actually measured before and in the year after the hurricane. However, we observed that, on exposed islands, C. erectus plants that had silver leaves before the hurricane sprouted green leaves a few months following the hurricane.

Our results are relevant to field experiments investigating the effect of browsing by moose on birch (Haukioja et al. 1990, Danell et al. 1997), rabbits on willows (Hjältén and Price 1996), and beavers on cottonwood (Martinsen et al. 1998): pruning or clipping apical buds resulted in increased susceptibility of the foliage to herbivorous arthropods. In one birch study, increased nitrogen, larger leaves, and other chemical and morphological changes were purportedly caused by a breakdown in apical dominance, which regulates the allocation of resources and other physiological processes throughout the plant (Haukioja et al. 1990). In our study, virtually all of the apical meristems were removed on the pruned shrubs. Thus, breaking apical dominance may have caused the pruned shrubs to produce vigorously growing shoots of foliage that are rich in nutrients and sugars and poor in proteinaceous material, making them more susceptible to herbivorous insects (Honkanen and Haukioja 1998). Many other cases of induced susceptibility by herbivores have been documented (Karban and Baldwin 1997). The present study links susceptibility to a climatic disturbance. Thus, any type of disturbance, physical or biological, that removes a large proportion of apical buds could increase the quality of leaves for herbivores in various ways. Because sprouting occurs on many woody plants following natural or anthropogenic disturbances (Del Tredici 2001), the findings in this study may have broad implications.

Other comparative studies of herbivory in forest trees following hurricanes have produced very different results. Schowalter and Ganio (1999) showed that, in a Puerto Rican rain forest after Hurricane Hugo, the abundance of defoliating insects and leaf area missing tended to be lower in heavily damaged areas (gaps) than in relatively undamaged sites, and that herbivore abundances and leaf area missing were not related to the concentration of nitrogen or other nutrients. However, their study began more than a year after the hurricane, whereas enhanced herbivory found in our comparative study did not last more than a year. Following Hurricane Opal in a North Carolina forest, Hunter and Forkner (1999) found that leaf area missing was substantially higher in damaged than in undamaged sites, even though their study was conducted more than a year after the hurricane. Surprisingly, concentrations of putative defensive compounds (foliar astringency, tannins) measured by Hunter and Forkner (1999) were higher in damaged than in undamaged sites. Therefore, some other factor caused higher folivory in damaged sites, despite higher astringency and tannins. In any case, previous studies show that the long-term effects (more than one year) of hurricanes on herbivory may vary considerably among systems. More studies of both short- and long-term responses are needed to evaluate the generality and importance of our results. In particular, strong immediate effects of hurricanes may have long-lasting impacts that ripple through the community over time (Wunderle 1995, Rathcke 2000).

In conclusion, this study has demonstrated that the effect of herbivores on plants was stronger when the exposed island communities were recovering from Hurricane Lili, compared to previously, when they were in a relatively steady state. Thus, in addition to direct negative effects on island populations (Spiller et al. 1998), the disturbance had profound indirect effects on food web dynamics. Another type of disturbance, periodic flooding, has also been shown to structure food webs in rivers (Power et al. 1996, Wootton et al. 1996). More generally, our observational data and experimental confirmation of the pattern contribute to the ongoing synthesis of how climatic factors can predictably alter biotic interactions (Dunson and Travis 1991, Hunter and Price 1992, Polis et al. 1997, Coley 1998).

\section{ACKNOWLEDGMENTS}

We thank E. Haukioja, R. Karban, S. Pennings, T. Schoener, J. Thaler, and an anonymous reviewer for comments, C. McCain and L. Morrison for field assistance, and NSF (DEB9904121) and NSERC (Natural Sciences and Engineering Research Council) for support.

\section{Literature Cited}

Agrawal, A. A. 1999. Induced responses to herbivory in wild radish: Effects on several herbivores and plant fitness. Ecology 80:1713-1723.

Baur, R., S. Binder, and G. Benz. 1991. Nonglandular leaf trichomes as short-term inducible defense of the gray alder, Alnus incana (L.), against the chrysomelid beetle, Agelastica alni L. Oecologia 87:219-226.

Bishop, J. G. 2002. Early primary succession on Mount St. Helens: impact of insect herbivores on colonizing lupines. Ecology 83:191-202.

Bond, W. J., and J. J. Midgley. 2001. Ecology of sprouting in woody plants: the persistence niche. Trends in Ecology and Evolution 16:45-51.

Cates, R. O., and G. H. Orians. 1975. Successional status and the palatability of plants to generalized herbivores. Ecology 68:1863-1876.

Coley, P. D. 1998. Possible effects of climate change on plant/ herbivore interactions in moist tropical forests. Climatic Change 39:455-472.

Coley, P. D., and J. A. Barone. 1996. Herbivory and plant defenses in tropical forests. Annual Review of Ecology and Systematics 27:305.

Connell, J. H. 1978. Diversity in tropical rain forests and coral reefs. Science 199:1302-1310.

Danell, K., E. Haukioja, and K. Huss-Danell. 1997. Morphological and chemical responses of birch leaves and 
twigs to winter browsing along a gradient of plant productivity. Ecoscience 4:296-303.

Del Tredici, P. 2001. Sprouting in temperate trees: a morphological and ecological review. Botanical Review 67: $121-140$

Dunson, W. A., and J. Travis. 1991. The role of abiotic factors in community organization. American Naturalist 138: 1067-1091.

Haukioja, E., K. Ruohomäki, J. Senn, J. Suomela, and M. Walls. 1990. Consequences of herbivory in the mountain birch (Betula pubescens ssp. tortuosa): importance of the functional organization of the tree. Oecologia 82:238-247.

Hjältén, J., and P. W. Price. 1996. The effect of pruning on willow growth and sawfly population densities. Oikos 77: 549-555.

Holt, R. D. 1996. Food webs in space. Pages 313-326 in G. A. Polis and K. O. Winemiller, editors. Food webs: integration of pattern and dynamics. Chapman and Hall, New York, New York, USA.

Honkanen, T., and E. Haukioja. 1998. Intra-plant regulation of growth and plant-herbivore interactions. Ecoscience 5: 470-479.

Hunter, M. D., and R. E. Forkner. 1999. Hurricane damage influences foliar polyphenolics and subsequent herbivory on surviving trees. Ecology 80:2676-2682.

Hunter, M. D., and P. W. Price. 1992. Playing chutes and ladders: heterogeneity and the relative roles of bottom-up and top-down forces in natural communities. Ecology $\mathbf{7 3}$ : $724-732$

Karban, R., and I. T. Baldwin. 1997. Induced responses to herbivory. University of Chicago Press, Chicago, Illinois, USA.

Lowman, M. D. 1984. An assessment of techniques for measuring herbivory: is rainforest defoliation more intense than we thought? Biotropica 16:264-268.

Lubchenco, J. 1986. Relative importance of competition and predation: early colonization by seaweeds. Pages 537-555 in J. Diamond and T. J. Case, editors. Community ecology. Harper and Row, New York, New York, USA.

Martinsen, G. D., E. M. Driebe, and T. G. Whitham. 1998 Indirect interactions mediated by changing plant chemistry: beaver browsing benefits beetles. Ecology 79:192-200.

Menge, B. A., and J. P. Sutherland. 1987. Community regulation: variation in disturbance, competition, and predation in relation to environmental stress and recruitment. American Naturalist 130:730-757.
Moon, D. C., and P. Stiling. 2000. Relative importance of abiotically induced direct and indirect effects on a saltmarsh herbivore. Ecology 81:470-481.

Polis, G. A., S. D. Hurd, C. T. Jackson, and F. Sanchez-Piñero. 1997. El Niño effects on the dynamics and control of an island ecosystem in the Gulf of California. Ecology 78: 1884-1897.

Power, M. E., M. S. Parker, and J. T. Wootton. 1996. Disturbance and food chain length in rivers. Pages 286-297 in G. A. Polis and K. O. Winemiller, editors. Food webs: integration of pattern and dynamics. Chapman and Hall, New York, New York, USA.

Rathcke, B. J. 2000. Hurricane causes resource and pollination limitation of fruit set in a bird-pollinated shrub. Ecology 81:1951-1958.

Rockwood, L. L. 1974. Seasonal changes in the susceptibility of Crescentia alata leaves to the flea beetle, Oedionychus sp. Ecology 55:142-148.

SAS Institute. 1999. SAS OnlineDoc. Version 8. SAS Institute, Cary, North Carolina, USA.

Schoener, T. W. 1988. Leaf damage in island buttonwood, Conocarpus erectus: correlations with pubescence, island area, isolation and the distribution of major carnivores. Oikos 53:253-266.

Schoener, T. W., D. A. Spiller, and L. W. Morrison. 1995. Variation in the hymenopteran parasitoid fraction on $\mathrm{Ba}$ hamian islands. Acta Oecologica 16:103-121.

Schowalter, T. W., and L. M. Ganio. 1999. Invertebrate communities in a tropical rain forest canopy in Puerto Rico following Hurricane Hugo. Ecological Entomology 24: 191-201.

Sousa, W. P. 1980. The response of a community to disturbance: the importance of successional age and species' life histories. Oecologia 45:72-81.

Sousa, W. P. 1984. The role of disturbance in natural communities. Annual Review of Ecology and Systematics 15: 353-391.

Spiller, D. A., T. W. Schoener, and J. B. Losos. 1998. Impact of a catastrophic hurricane on island populations. Science 281:695-697.

Wootton, J. T., M. S. Parker, and M. E. Power. 1996. Effects of disturbance on river food webs. Science 273:1558-1560.

Wunderle, J. M., Jr. 1995. Responses of bird populations in a Puerto Rican forest to Hurricane Hugo: the first 18 months. Condor 97:879-896. 